\title{
A Study of Assessment of Partial Edentulous Patients Based on Kennedy's Classification at Dhulikhel Hospital Kathmandu University Hospital
}

\author{
Sapkota B, Adhikari B, Upadhaya C
}

\author{
Department of Dentistry \\ Dhulikhel Hospital- Kathmandu University Hospital \\ Kathmandu University School of medical Science \\ Dhulikhel, Kavre, Nepal
}

Corresponding Author

Binam Sapkota

Department of Dentistry

Dhulikhel Hospital- Kathmandu University Hospital

Kathmandu University School of medical Science

Dhulikhel, Kavre, Nepal

E-Mail: s_binam@yahoomai.com

Citation

Sapkota B, Adhikari B, Upadhaya C. A Study of Assessment of Partial Edentulous Patients Based on Kennedy's Classification at Dhulikhel Hospital, Kathmandu University Hospital. Kathmandu Univ Med J 2013;44(4)325-:327.

\section{ABSTRACT}

\section{Background}

Oral health contributes significantly towards quality of life(QOL). Edentulousness falls in a special category among the various conditions of dental origin. Dietary intake and nutritional status is affected by poor oral health and loss of teeth. This will ultimately compromise general health.

\section{Objective}

To identify the frequency of Kennedy's classification among partial edentulous patients and to compare occurrence among gender and between upper and lower arches and also to compare edentulousness among employed and unemployed population.

\section{Methods}

This study was carried out at Dhulikhel Hospital Dental Department. The study was conducted randomly among 194 patients in dental OPD who were partially edentulous. A structured pro forma was used to find out the edentulousness based on Kennedy,s classification.

\section{Results}

Among the Kennedy's classification Classlll was found to be most common. Among them females and unemployed group were found to have more edentulousness and upper arch was more common. It was also found that females were more conscious and get the replacement of missing teeth among which those having Class IV missing were replaced most often.

\section{Conclusion}

The Kennedy Class III partial edentulousness type is most commonly found in this study.

\section{KEY WORDS}

Edentulousness, kennedy's classification

\section{INTRODUCTION}

The World Health Organization defines health as "a state of complete physical, mental and social well being,not merely the absence of disease or infirmity (WHO 1980). This modern approach to health lends itself to oral health as well. ${ }^{1}$

Oral health contributes significantly towards quality of life (QOL). ${ }^{2}$ Poor oral health and loss of teeth adversely affect the dietary intake and nutritional status. Which ultimately compromise general health and also deny them the pleasure of taking food of their choice. ${ }^{3}$
A number of factors are known to be associated with the oral health, such as socio-economic status, literacy level and marital status, smoking or chewing tobacco and alcohol consumption. Other factors such as oral hygiene practices, social and cultural beliefs and attitudes, perception regarding oral health and function, and philosophy of the dentist, can all influence oral health. ${ }^{4}$ Also the patients past experience with denture and with dentist affects their attitude towards dentist and denture wearing.

A major challenge for dental profession is to plan oral 
health care. For prevention and treatment of oral diseases information is required about the reason for extraction of permanent teeth. The primary purpose of removable partial denture must always be as, Muller De Van (1952) stated "the preservation of that which remains and not the meticulous replacement of that which has been lost". ${ }^{2}$

This study assess the frequency of various Kennedy's classification among the partial edentulous and comparision between the gender group and among employed and unemloyed and also most common edentulousness between upper arch and lower arch and most commonly replaced among the classification.

\section{METHODS}

This study was carried out at Department of Prosthodontics, Dhulikhel Hospital. After the approval from institutional review committee, study was conducted randomly among 194 patients visited dental out patient department from July- September 2013. The written consent was acquired before enrolling them to the study. Only partially edentulous patients of age group 25-50 years and having permanent dentition were included in this study. Patients were interviewed and information was filled in the structured pro forma. The same dental surgeon was involved in interviewing and filling the pro forma who performs oral examination. The oral examination was performed using the Kennedy's and the Applegate-Kennedy classification.

\section{Kennedy's classification:}

Class-I: Bilateral edentulous area located posterior to the remaining natural teeth.

Class-II: Unilateral edentulous area located posterior to the remaining natural teeth.

Class-III: A unilateral edentulous area with natural teeth both anterior and posterior to it.

Class-IV: Single but bilateral edentulous area located anterior to the remaining natural teeth.

\section{Applegate-Kennedy classification:}

Class-V: An edentulous situation in which teeth bound, anterior and posterior but the anterior boundary tooth not suitable for abutment.

Class-VI: Edentulous situation in which boundary teeth are capable of total support of required prosthesis.

\section{RESULT}

Out of 194 patients, there were 83 males and 111 were females and $52.5 \%$ of them were un-employed and the rest were employed.

Gender-wise distribution in relation to Kennedy's classification in upper arch shows 70 Males and 56 Females of which Class III ( $n=89$ ) was found to be the most common
(Table 1). Similarly the Kennedy's classification in lower arch revealed 67 Males and 70 Females (Table 2). In lower arch also, the most common class was found to be Class III $(n=83)$ which is similar to the upper arch.

Table 1. Gender and Kennedy's classification in Relation to Upper Arch.

\begin{tabular}{|ccc|}
\hline Upper arch & Male & Female \\
\hline Class I & 5 & 2 \\
\hline Class II & 12 & 17 \\
\hline Class III & 52 & 37 \\
\hline Class IV & 1 & 0 \\
\hline Total & 70 & 56 \\
\hline
\end{tabular}

Table 2. Gender and Various Kennedy's classification in Lower Arch.

\begin{tabular}{|ccc|}
\hline Lower arch & Male & Female \\
\hline Class I & 6 & 1 \\
\hline Class II & 13 & 13 \\
\hline Class III & 35 & 48 \\
\hline Class IV & 13 & 8 \\
\hline Total & 67 & 70 \\
\hline
\end{tabular}

Moreover, while comparing among different classes, the most common class was found to be the Kennedy's Class III in both the arches (Table 3). The present study shows the higher employment status in male ( $n=62$; Table 4 ) though, our result shows that female were more concern and wear dentures more commonly than males. Among denture wearers, 25 were found to be males while 31 were females (Table 5).

Table 3. Comparision of Kennedy's classicification in Relation to Upper and Lower Arch.

\begin{tabular}{|ccc|}
\hline Lower arch & Male & Female \\
\hline Class I & 6 & 1 \\
\hline Class II & 13 & 13 \\
\hline Class III & 35 & 48 \\
\hline Class IV & 13 & 8 \\
\hline Total & 67 & 70 \\
\hline
\end{tabular}

Table 4. Shows Gender Distribution Among Employed and Unemployed.

\begin{tabular}{|ccc|}
\hline Employment status & Male & Female \\
\hline Employed & 62 & 30 \\
\hline Unemployed & 21 & 81 \\
\hline
\end{tabular}

Table 5. Gender Distribution Among Denture Wearer and Non Denture Wearer.

\begin{tabular}{|ccc|}
\hline Denture status & Male & Female \\
\hline Denture wearer & 25 & 31 \\
\hline Non-denture wearer & 58 & 72 \\
\hline
\end{tabular}




\section{DISCUSSION}

It is believed that with increasing age, oral and dental problems increases. Although with increasing age, there is decline in taste and smell, which can influence the status of oral health and function: age alone is not responsible for the deterioration of oral health. ${ }^{5}$ Other contributing factors are socioeconomic factors and psychological factors such as depression and isolation leading to negligence of personal oral hygiene and health. ${ }^{6}$

Patients of age group 25-50 years were surveyed as this category exhibited maximum partial edentulousness. ${ }^{3}$ Our study shows a higher proportion of females were edentulous compared to male. This is in agreement with study by Udani. ${ }^{7}$ However, some earlier studies showed more male being edentulous than female..$^{8,9}$ This contradiction may be due to the different socio-economic background and mal-habits like smoking and consumption of high sugar containing diets.

In addition, female in this study had a lower level of employment status, because of which they are more dependent to males. This could be a possible reason for female being partially edentulous as they cannot opt for needed treatment to save teeth. ${ }^{2}$ Also similar result was found in the study done among the people aged above 65 years in Turkey which also shows low literacy level and female gender to be high-risk groups for tooth loss. ${ }^{10}$ Further, it was also observed that more unemployed people were partially edentulous than employed. ${ }^{11}$ The reason behind this could be the level of education. It is understood that employment is directly proportional to education so educated people are more concerned about their health requirement so they seek for dental treatment earlier than uneducated people who go for treatment only when it is emergency which is also in agreement with the study done by Pallegedara and Ekanayake. ${ }^{12}$

Interestingly, our study shows that the percentage of replacement of missing teeth was higher in females. Women have better health seeking behaviors and more conscious for their appearance and this could be one of the main reasons that females are visiting dental clinic more frequently than male. ${ }^{2}$

In the present study, Kennedy Class III is more frequent type followed by Class II, Class IV and Class I in the age group 25-50 years. In support to our findings, Shah et al have shown the similar result. ${ }^{2}$ Furthermore, the study also has shown that the most common in maxilla than in mandible which is also true in our study. ${ }^{2}$ The poor oral hygiene and inaccessibility for proper cleaning could be the possible reason which ultimately leads to tooth decay and requirement for tooth extraction. Of various classes a higher number of subjects with Class IV got their teeth replaced may be due to esthetic reasons, followed by Class II and Class I for mastication. Class III has the least percentage of replacement which may be due to patient's negligence as the position of tooth to be replaced is not visible and also do not affect the patient's appearance. Furthermore, one study has shown the less percentage of replacement which is similar to the present study. ${ }^{12}$ This could be due to the high cost for the tooth replacement, patients do not opt for this option though there are various options like removable partial denture, fixed partial denture and dental implants.

\section{CONCLUSION}

The study concluded that among the Kennedy classification Class III is the most common among the age group 25-50 years. Maxillary partial edentulism was found to be more than mandibular partial edentulism. There is reduction in edentulousness with employment status. Unemployed females and unemployed groups were more edentulous.

Therefore, an awareness regarding poor oral health, timely oral checkup with necessary replacement of missing teeth is required. It is essential that tooth loss should be avoided as far as possible as it ultimately affects in our overall health. If teeth have to be extracted or where teeth have already been lost, prosthodontic rehabilitation should be provided to stabilize the arch and restore the comfort and function.

\section{REFERENCES}

1. Chalise HN. Demographic situation of population ageing in Nepal. Kathmandu UnivMed J. 2006 Jul-Sep;4(3):354-362.

2. Shah $\mathrm{N}$, Parkash $\mathrm{H}$, Sunderam KR." Edentulousness, denture wear and denture needs of Indian elderly -a community based study'. J Oral Rehabilitation. 2004 May;31(5):467-76.

3. Chauncey HH, Muench ME, KapurKK, Wayler AH. The effect of loss of teeth on diet and nutrition in elderly. Int Dent J. 1984 Jun;34(2):98104.

4. Berkey DB, Berg RG, EttingerRL, Mersel A, Mann J. The old-olddental patient: the challenge of clinical decision-making. J Am Dent Assoc. 1996 Mar; 127(3):321-332.

5. Estien S. Importance of psychosocial and behavioral factors in food ingestion in the elderly and their ramification on oral health. Gerodontics. 1987 Feb;3(1):23-25.

6. Locker D, Slade G. Association between clinical and subjective indicators of oral health status in an older adult population. Gerodontology. 1994 Dec; 11(2):108-114.

7. Udani TM. Age incidence of Indian patients in need of full denture service. J Ind Dent Assoc. 1954 Jul; 26:5.

8. Swominen - Taipale AL, Alalen P, Helenius H, Nordblad A, Uutela A. Edentulism among Finnish adults of working age,1978-1997. Community Dent Oral Epidemiol. 1999 Oct;27(5):353-65.

9. Hoover JN, Mc Dermott RE. Edentulousness in patient attending a University Dental clinic. J Can Dent. Assoc. 1989 Feb;55(2):139-40.

10. Nalcaci R, ErdemirEO, Baran I. Evaluation of the oral health status of the people aged 65 years and over living in near rural district of Middle Anatolia,Turkey. Arch Geronto/Geriatr. 2007 Jul-Aug;45(1):55-64.

11. EttingerRL, Beck JD,Jakobsen J. Removable prosthodontictreatment needs:A survey. J Prosthet Dent. 1984 Mar;51(3):419-27.

12. Pallegedara C, Ekanayake L. Tooth loss,the wearing of dentures and associated factors in Sri Lankan older individuals. Gerodontology. 2005 Dec;22(4):193-9. 